\title{
Characterization of Strontium Adsorption from Aqueous Solutions Using Inorganic Materials Impregnated with Ionic Liquid
}

\author{
Adina Negrea, Lavinia Lupa, Mihaela Ciopec, and Petru Negrea
}

\begin{abstract}
New materials were obtained by impregnation of trihexyltetradecylphosphonium chloride (Cyphos IL-101) onto Florisil and Silica in order to be used as adsorbent in the removal process of $\mathrm{Sr}^{2+}$ from aqueous solutions. The obtained materials were characterized through FT-IR, SEM, EDX, and BET analysis. The adsorption process has been investigated as a function of $\mathrm{pH}$, solid:liquid ratio, adsorbate concentration, contact time and temperature. The isotherm data were well described by Langmuir isotherm model. The maximum adsorption capacities was found to be $2.94 \mathrm{mg} \mathrm{Sr} \mathrm{Sr}^{2+} \mathrm{g}$ of adsorbent in case of Florisil and for Silica impregnated with Cyphos IL-101 is $3.97 \mathrm{mg} \mathrm{Sr}^{2+} / \mathrm{g}$ of adsorbent. The results indicate that the adsorption fitted well with the pseudo-second order kinetic model.
\end{abstract}

Index Terms- $\mathrm{Sr}^{2+}$ adsorption, Cyphos IL-101, isotherm model, kinetic model.

\section{INTRODUCTION}

A major problem that the society must face today is the necessity to minimize the amount of waste discharge in the environment. For instance, strontium has a variety of commercial and research use like: in the manufacture of X-ray absorbing glass for cathode ray tubes, in the electrolytic zinc process, electroceramics and oxide superconductors. From all these industry results wastes and secondary products which will severely pollute the environment if the wastes are not treated well [1], [2]. The ingestion of $\mathrm{Sr}^{2+}$ can lead to the replace of the $\mathrm{Ca}^{2+}$ from the human body due to the chemical similarity of these two ions, and this fact can cause different illnesses. Therefore, the separation of $\mathrm{Sr}^{2+}$ ions from waste solutions is very important [3]-[5] A new trend in the treatment of the radioactive waste solutions is the use of the ionic liquids (IL) due to their "green" properties [6]-[11]. Instead of the liquid-liquid extraction, was found, that the immobilization of the ionic liquids in a suitable solid supports is more suitable for the metal ions removal from aqueous solutions because is avoid the loss of ionic liquid, and the generation of a great amount of organic waste resulting from the hydrolytic and radiolytic degradation of the extractants and diluents [8], [9], [11]. In addition, the use of IL-impregnated supports, in the removal process of metals ions from aqueous solutions, increase the selectivity and the degree of adsorbent-adsorbate interaction,

Manuscript received July 2, 2013; revised September 6, 2013.

The authors are with the University "Politehnica" Timisoara, Faculty of Industrial Chemistry and Environmental Engineering, Blvd. Vasile Parvan, no. 6, 300223, Timisoara, Romania (email: lavinia.lupa@ chim.upt.ro). due to the combine advantages between the solvent extraction and the mechanical stability of the solid support [8]-[17].

The main objective of this research is to study the adsorption performance of two inorganic solid supports (Florisil and Silica) impregnated with trihexyltetradecylphosphonium chloride (Cyphos IL-101) in the removal process of $\mathrm{Sr}^{2+}$ ions from aqueous solutions. We focused on the inorganic solid supports due to their several superior advantages: higher thermal and chemical stabilities, well-ordered periodic pore structure, and controllable pore diameter, and particularly in liquid radioactive waste treatment: radiation stability and great selectivity for certain radiological important species [11], [17]-[20].

\section{EXPERIMENTAL}

\section{A. Adsorption Preparation and Characterization}

The Florisil and Silica inorganic supports (purchased from Merck) were impregnated with Cyphos IL-101 (Sigma-Aldrich) via the dry method of impregnation. Before impregnation method the various quantity of Cyphos IL-101 $(0.05,0.1,0.2,0.4,0.6 \mathrm{~g})$ were dissolved in $5 \mathrm{~mL}$ of ketone. 5 $\mathrm{g}$ of each inorganic solid support were treated with $25 \mathrm{~mL}$ of ketone (containing the IL in the ratio mentioned before), for 24 hours at room temperature. After impregnation the suspensions were dried in an oven overnight at $50^{\circ} \mathrm{C}$. In the first step the optimum quantity of the IL impregnated onto the solid supports was established by studding the dependence of the adsorption capacity of the obtained impregnated materials, in the removal process of $\mathrm{Sr}^{2+}$ from aqueous solutions, versus of the ratio IL: solid support. In order to confirm that the studied solid supports were impregnated with the established optimum quantity of Cyphos IL-101, the obtained impregnated materials were characterized by Fourier transform infrared spectroscopy FTIR, energy dispersive $\mathrm{X}$-ray analysis (EDX), scanning electron microscopy (SEM) and BET - accelerated surface area analysis.

The FTIR spectra ( $\mathrm{KBr}$ pellets) of the obtained materials were recorded on a Shimadzu Prestige- 21 FTIR spectrophotometer in the range $4000-400 \mathrm{~cm}^{-1}$. The surface morphology of the impregnated materials was investigated by Scanning Electron Microscopy (SEM) using a Quanta FEG 250 Microscope, equipped with EDAX ZAF quantifier. The BET surface area of the samples obtained by both methods has been established by nitrogen adsorption-desorption using a Quanta - chrome Nova 1200 Equipment. 


\section{B. Adsorption Experiments}

Adsorption studies were carried out by batch technique using a Julabo SW23 shaker with a constant shaking rate. To determine the $\mathrm{pH}$ range at which the maximum uptake of $\mathrm{Sr}^{2+}$ would take place onto the impregnated solid support (ISS), a well determined quantity of the ISS $(0,1 \mathrm{~g})$ was treated with $25 \mathrm{~mL}$ of $\mathrm{Sr}^{2+} 10 \mathrm{mg} / \mathrm{L}$ solution having various initial $\mathrm{pH}$ values range from 2 to 8 , for 2 hours at $298 \mathrm{~K}$. The $\mathrm{pH}$ of the synthetic solutions was adjusted using $0.1 \mathrm{~N} \mathrm{NaOH}$ or $0.1 \mathrm{~N}$ $\mathrm{HCl}$, in order to attain the desired $\mathrm{pH}$ for a specific period of contact time. After the establishment of the optimum $\mathrm{pH}$, the influence of various $S$ : L ratio on the efficiency of adsorption process was studied. After the time elapsed the sample were filtered and the $\mathrm{Sr}^{2+}$ ion concentration was determined through atomic emission spectrometry using a Varian SpectrAA 280 type atomic absorption spectrometer using air/acetylene flame.

The adsorption performance of the ISS was expressed as the $\mathrm{Sr}^{2+}$ uptake, $q, \mathrm{mg} / \mathrm{g}$, and the corresponding mass balance expression is:

$$
q_{e}=\frac{\left(C_{0}-C_{e}\right) \cdot V}{m}
$$

where: $C_{0}$ and $C_{t}$ are the concentrations of $\mathrm{Sr}^{2+}$ ions $(\mathrm{mg} / \mathrm{L})$ in the solution initially $(t=0)$ and at equilibrium, respectively, $V$ is the volume of the solution and $m$ is the mass of adsorbent.

Adsorption isotherm were studied by mixing a known amount of ISS $(0.1 \mathrm{~g})$ with various initial $\mathrm{Sr}^{2+}$ concentration raging from 5 to $50 \mathrm{mg} / \mathrm{L}$ at $298 \mathrm{~K}$ and a $\mathrm{pH}=6$. The experimental data obtained were tested with Langmuir and Freundlich isotherm. Linear regression is frequently used to determine the best-fitting isotherm, and the applicability of isotherm equations is compared by judging the correlation coefficients.

In order to compare the ability of ISS, the effect of contact time on the adsorption of $\mathrm{Sr}^{2+}$ was investigated. In this purpose $0.1 \mathrm{~g}$ of the ISS were treated with $25 \mathrm{~mL}$ of $\mathrm{Sr}^{2+}$ various time (range from 30 to 240 minutes) at three temperatures $(298 \mathrm{~K}, 308 \mathrm{~K}$ and $318 \mathrm{~K})$. In this work, the batch data will be applied to selected adsorption kinetic models, namely pseudo-first-order and pseudo-second-order models.

\section{RESULTS AND DisCUSSION}

\section{A. Impregnated Solid Support Characterization}

The dependence of the adsorption capacity of the ISS versus of the quantity of IL impregnated onto the solid supports (SS) in the removal process of $\mathrm{Sr}^{2+}$ from aqueous solutions is presented in Fig. 1.

It can be observed that the increase of the quantity of the IL impregnated onto the SS doesn't lead to a significant increasing of the adsorption capacity of the ISS in the removal process of $\mathrm{Sr}^{2+}$ from aqueous solutions. Therefore is considered that $0.1 \mathrm{~g}$ is the optimum quantity of the IL to be impregnated onto $1 \mathrm{~g}$ of solid support.

The Fourier Transform infrared spectroscopic analysis of the studied inorganic solid supports after impregnation with the optimum quantity of IL was studied (Fig. 2). The FT-IR spectra confirmed the fact that the impregnation occurs due to the fact that in the spectrum of the SS after impregnation with the studied IL occurs a few characteristic peaks of the studied IL (at $2931 \mathrm{~cm}^{-1}$ which is assigned to the asymmetric vibration $v_{\text {asym }} \mathrm{CH}_{3}^{+} v_{\text {asym }} \mathrm{CH}_{2}$ and the band at $2858 \mathrm{~cm}^{-1}$ which is attributed to the symmetric vibration $v_{\text {asym }} \mathrm{CH}_{3}^{+} v_{\text {asym }}$ $\mathrm{CH}_{2}$ ), which are not present in the spectrum of the SS before impregnation.

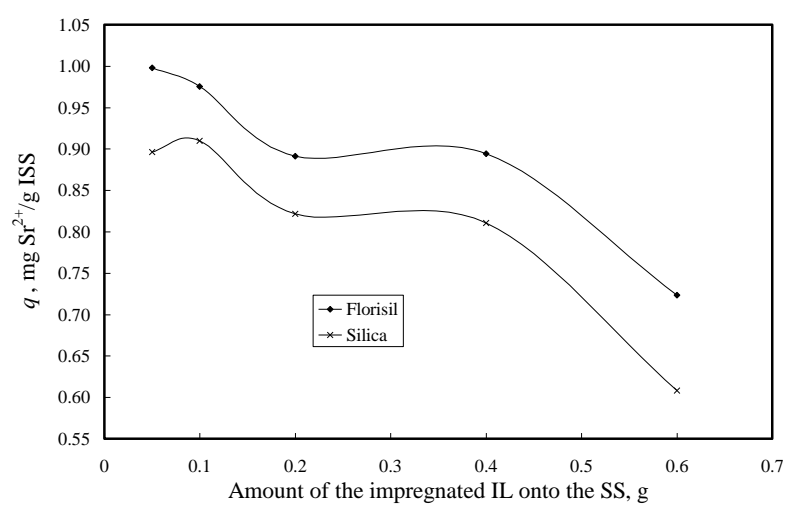

Fig. 1. The influence of the quantity of the IL impregnated onto the SS

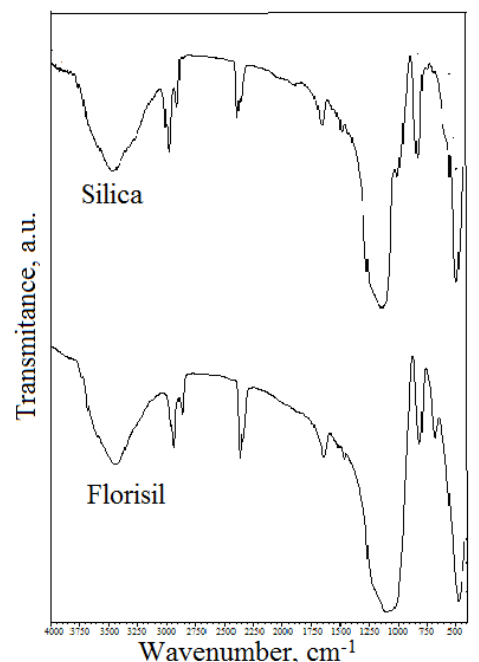

Fig. 2. FT-IR spectra of the ISS

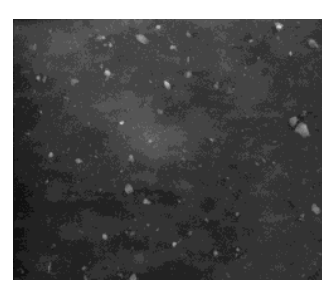

a) Florisil

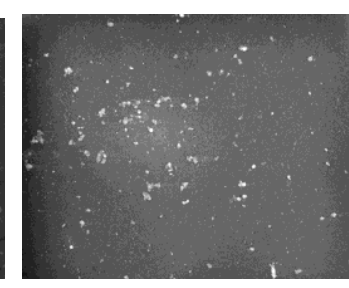

b) Silica
Fig. 3. SEM-images of the studied SS after impregnation with Cyphos IL-101

The morphological structures of ISS can be observed from the SEM-images presented in Fig. 3. It can be observed that onto the smooth surface of the solid supports (Florisil and Silica) are bounded the fine particles of the IL. The particles of the IL are more abundant in the case of silica solid support.

The characteristic of the obtained ISS resulted at EDX and BET analysis are presented in Table I.

One can be notice that the surface area and the pore 
volume of the Silica samples are higher then the Florisil samples, also the quantity of the IL impregnated onto the SS is confirmed by the concentration of $\mathrm{P}$ and $\mathrm{Cl}$ which is specific for the studied IL, Chypos IL-101. From the results obtained from the analysis of the ISS we aspect to obtain a higher adsorption capacity in the removal process of $\mathrm{Sr}^{2+}$ ions from aqueous solutions in the case of use as adsorbent of the Silica impregnated solid support.

TABLE I: THE CHARACTERISTIC OF THE OBTAINED ISS RESULTED AT EDX AND BET ANALYSIS

\begin{tabular}{ccccc}
\hline \hline $\begin{array}{c}\text { Solid } \\
\text { support }\end{array}$ & $\mathrm{P}$, wt $\%$ & $\mathrm{Cl}$, wt $\%$ & $\begin{array}{c}\text { BET surface } \\
\text { area, } \mathrm{m}^{2} / \mathrm{g}\end{array}$ & $\begin{array}{c}\text { Pore volume, } \\
\mathrm{cm}^{3} / \mathrm{g}\end{array}$ \\
\hline $\begin{array}{c}\text { Florisil } \\
\text { Silica }\end{array}$ & 0.28 & 0.67 & 138.07 & 0.32 \\
\hline \hline
\end{tabular}

\section{B. Effect of $p H$}

The $\mathrm{pH}$ of the solution has been identified as control parameter in the removal process of metal ions from aqueous solutions. The effect of $\mathrm{pH}$ on the adsorption capacity of the studied ISS is presented in Fig. 4.

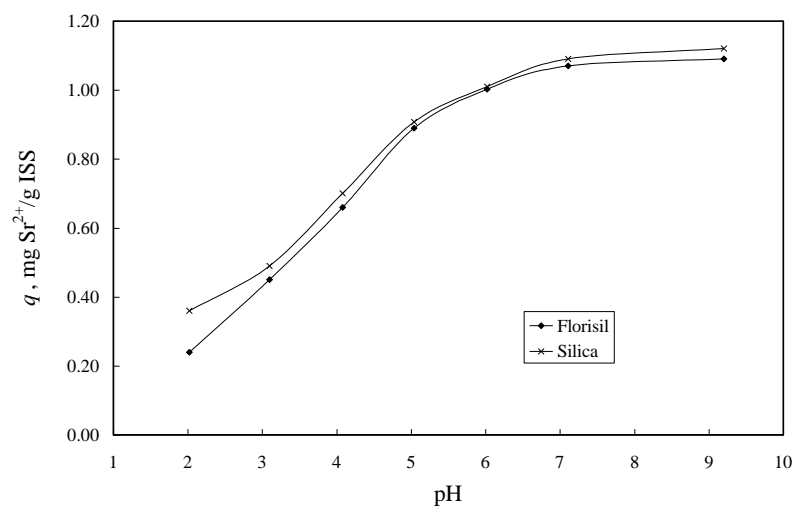

Fig. 4. The effect of $\mathrm{pH}$ on the $\mathrm{Sr}^{2+}$ adsorption onto ISS

As seen in Fig. 4 the adsorption capacity of the ISS increase with the increasing of the initial $\mathrm{pH}$ of $\mathrm{Sr}^{2+}$ solution. The higher adsorption levels were obtained for $\mathrm{pH}$ between 6 and 8 . Therefore the $\mathrm{pH}=6$ was selected for further adsorption experiments.

\section{Effect of S:L Ratio}

In order to establish the optimum quantity of the ISS used in the removal process of $\mathrm{Sr}^{2+}$ from aqueous solutions, the effect of $\mathrm{S}$ : $\mathrm{L}$ ratio onto the adsorption performance, was studied. The experimental data are presented in Fig. 5.

Due to the fact that the adsorption capacity is related to the amount of the adsorbent used in the removal process, with the increasing of the $S$ : L ratio decrease the adsorption capacity of the studied ISS. Therefore the further experiments were used at a $\mathrm{S}: \mathrm{L}=0.1: 25$, which is considered the optimum $\mathrm{S}: \mathrm{L}$ ratio for the removal process of $\mathrm{Sr}^{2+}$ from aqueous solutions through adsorption onto ISS.

\section{Adsorption Isotherm}

Adsorption isotherms are used to express the surface properties and affinity of the adsorbent and can also be used to compare the adsorption capacities of the sorbents for pollutants in aqueous solutions.

The adsorption isotherm of $\mathrm{Sr}^{2+}$ onto the ISS is presented in Fig. 6. The adsorption capacities approach constant values at high equilibrium concentrations. These values represent the experimentally determined maximum adsorption capacities of $\mathrm{Sr}^{2+}$ onto the studied ISS.

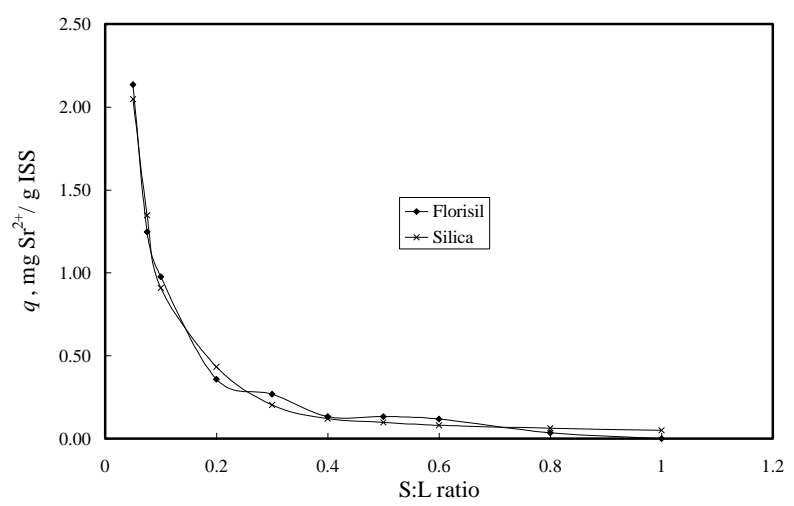

Fig. 5. The effect of $\mathrm{S}: \mathrm{L}$ ratio on the $\mathrm{Sr}^{2+}$ adsorption onto ISS

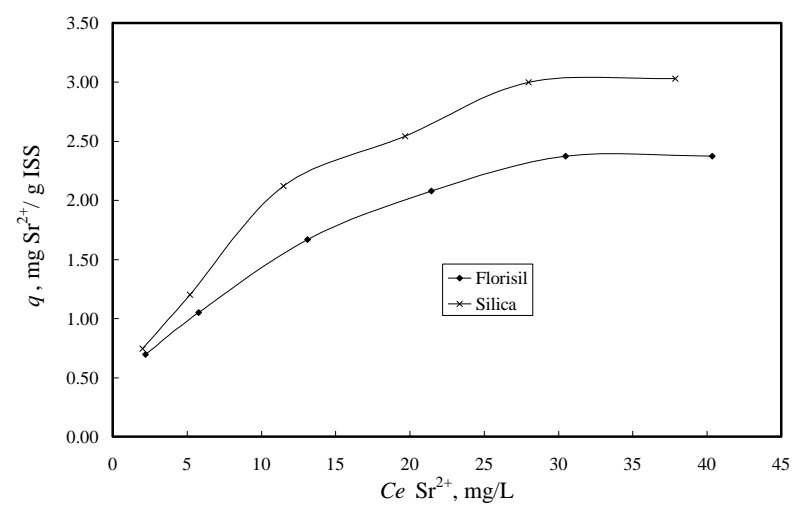

Fig. 6. Adsorption isotherm of $\mathrm{Sr}^{2+}$ onto the studied ISS

The Langmuir and Freundlich isotherm studies were conducted in order to determine the maximum adsorption capacities of Florisil, respective Silica towards $\mathrm{Sr}^{2+}$. The Langmuir isotherm applies to adsorption on completely homogenous surfaces with negligible interaction between adsorbed molecules. This theory considers that all surface sites have the same adsorption energy [5]. The relation between the amount of adsorbate adsorbed by the adsorbent can be expressed by the linearized Langmuir adsorption isotherm as:

$$
\frac{C_{e}}{q_{e}}=\frac{1}{K_{L} \cdot q_{m}}+\frac{C_{e}}{q_{m}}
$$

where $q_{e}$ is the amount of $\mathrm{Sr}^{2+}$ adsorbed onto ISS, $K_{L}$ and $q_{m}$ are Langmuir constants representing the equilibrium constant for the adsorbate-adsorbent equilibrium and the monolayer capacity. These parameters can be calculated from the slope and intercept of the linear plot resulted from the representation of $\mathrm{Ce} / q e$ versus $\mathrm{Ce}$ (Fig. 7).

The Freundlich model is an empirical equation and can be applied for non-ideal sorption on heterogeneous surfaces and multilayer sorption [5]. The Freundlich equation is expressed by the following equation.

$$
\ln q_{e}=\ln K_{F}+\frac{1}{n} \cdot \ln C_{e}
$$

where $q_{e}$ is the amount of adsorbate adsorbed per unit of the 
adsorbent $(\mathrm{mg} / \mathrm{g}), C_{e}$ the equilibrium concentration of $\mathrm{Sr}^{2+}$ $(\mathrm{mg} / \mathrm{L})$, and $n$ and $K_{F}$ are the constants depending upon the nature of the adsorbate and adsorbent where $n$ represents the adsorption intensity and $K_{F}$ represents the adsorption capacity $(\mathrm{mg} / \mathrm{g})$. Freundlich isotherm for the adsorption was drawn by plotting $\ln q_{e}$ versus $\ln C_{e}$ (Fig. 8). The calculated parameters, as well as the correlation coefficients $\left(R^{2}\right)$ for $\mathrm{Sr}^{2+}$ removal through adsorption onto ISS are presented in Table II.

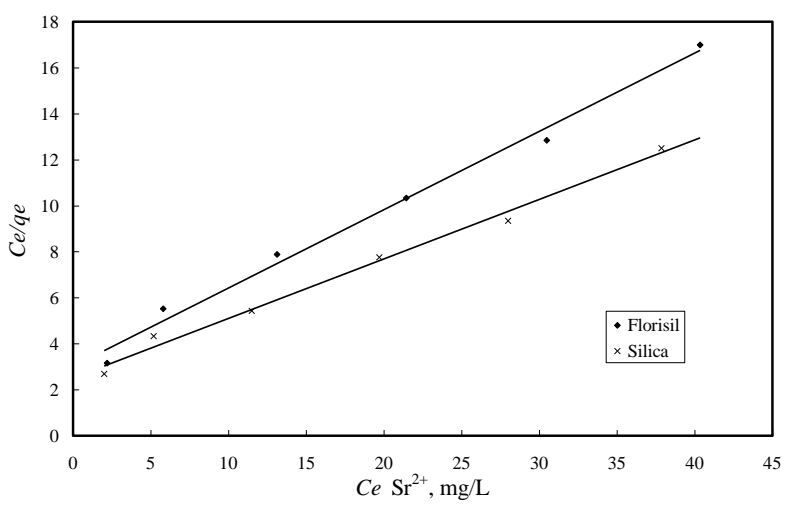

Fig. 7. Langmuir isotherm plots for $\mathrm{Sr}^{2+}$ adsorption onto ISS

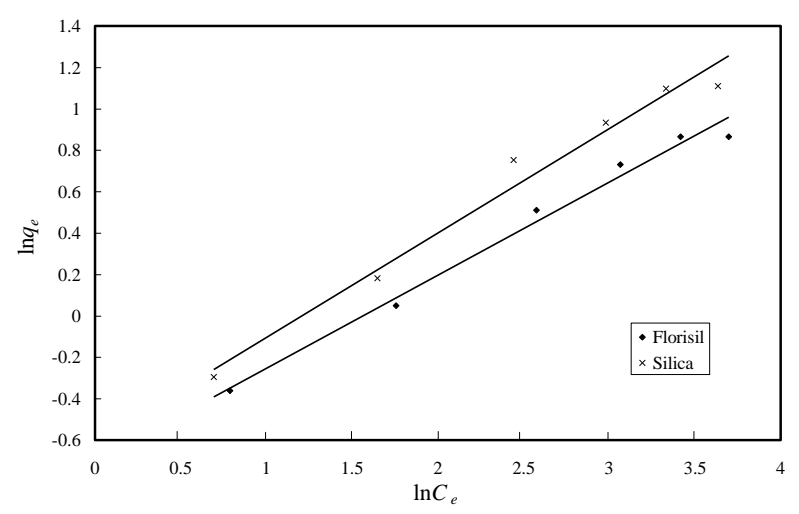

Fig. 8. Freundlich isotherm plots for $\mathrm{Sr}^{2+}$ adsorption onto ISS

TABLE II: PARAMETERS OF LANGMUIR AND FREUNDLICH ISOTHERMS FOR $\mathrm{SR}^{2+}$ IONS ADSORPTION ONTO ISS

\begin{tabular}{cccccccc}
\hline \hline & & \multicolumn{3}{c}{ Langmuir isotherm } & \multicolumn{3}{c}{ Freundlich isotherm } \\
\cline { 3 - 8 } Adsorb. & $q_{m, \exp }$ & $K_{L}$ & $q_{m, \text { calc }}$ & $R^{2}$ & $K_{F}$ & $1 / n$ & $R^{2}$ \\
& $\mathrm{mg} / \mathrm{g}$ & $\begin{array}{c}\mathrm{L} / \mathrm{mg} \\
\mathrm{mg} / \mathrm{g}\end{array}$ & & $\mathrm{mg} / \mathrm{g}$ & & \\
\hline Florisil & 2.37 & 0.113 & 2.94 & 0.9909 & 0.495 & 0.4498 & 0.9857 \\
Silica & 3.03 & 0.100 & 3.97 & 0.9912 & 0.513 & 0.5043 & 0.9783 \\
\hline \hline
\end{tabular}

The Freundlich plots (Fig. 8) have low regression coefficients suggesting a restriction on the use of Freundlich isotherm. The constants $K_{F}$ and $1 / n$ computed from the linear plot are presented in Table II. The constant $K_{F}$ can be defined as an adsorption coefficient which represents the quantity of adsorbed metal ions for a unit equilibrium concentration. The slope $1 / n$ is a measure of the adsorption intensity or surface heterogeneity. For $1 / n=1$, the partition between the two phases is independent on the concentration. The situation $1 / n$ $<1$ is the most common and correspond to a normal L-type Langmuir isotherm, whilst $1 / n>1$ is indicative of a cooperative adsorption which involves strong interactions between the molecules of adsorbate. Values of $1 / n<1$ show favorable adsorption of $\mathrm{Sr}^{2+}$ ions onto the studied materials. The Langmuir model effectively describes the sorption data for all the studied materials with correlation coefficient closer to 1 . Thus the isotherm follows the sorption process in the entire concentration range studied for both materials. Moreover the maximum adsorption capacities of the ISS obtained from the Langmuir plot are very close to those experimentally obtained. The maximum adsorption capacities of $\mathrm{Sr}^{2+}$ developed by Silica impregnated with Cyphhos IL-101 is higher then the adsorption capacities of $\mathrm{Sr}^{2+}$ developed by the Florisil impregnated with Cyphos IL-101. This is in accordance with the conclusion resulted from the EDX and BET surface area.

The adsorption capacities $\left(q_{m}\right)$ of different adsorbents for adsorption of $\mathrm{Sr}^{2+}$ ions are compared in Table III. It may be seen the studied materials present exhibit a good adsorption capacities compared with other studied materials.

TABLE III: ADSORPTION CAPACITY OF VARIOUS ADSORBENTS IN THE REMOVAL PROCESS OF $\mathrm{SR}^{2+}$ FROM AQUEOUS SOLUTIONS

\begin{tabular}{ccc}
\hline \hline Adsorbent & $\boldsymbol{q}_{\boldsymbol{m}, \mathbf{m g} / \mathbf{g}}$ & Reference \\
\hline PAN/zeolite & 0.011 & {$[4]$} \\
Dolomite & 1.172 & {$[5]$} \\
Hydrous ceric oxide & 0.106 & {$[21]$} \\
Chromium (IV) oxide & 0.055 & {$[21]$} \\
Florisil impregnated with Cyphos IL-101 & 2.94 & Present work \\
Silica impregnated with Cyphos IL-101 & 3.97 & Present work \\
\hline \hline
\end{tabular}

The dimensionless constant, called separation factor (RL) can be used to describe the essential characteristics of a Langmuir isotherm.

$$
R_{L}=\frac{1}{1+K_{L} \cdot C_{0}}
$$

where the terms have their meanings as stated above. In fact, the separation factor is a measure of the adsorbent capacity used. Its value decreases with increasing " $K_{L}$ " as well as initial concentration. $R_{L}$ values can be related to the equilibrium isotherm as follows: unfavourable, $R_{L}>1$; linear, $R_{L}=1$; favourable $0<R_{L}<1$; and irreversible, $R_{L}=0$.

The values were calculated for the entire concentration range studied and the results are found to lie in between 0 and 1 , in all the cases, demonstrating a favorable sorption process of $\mathrm{Sr}^{2+}$ onto studied ISS.

\section{E. Adsorption Kinetics}

The effect of contact time onto the adsorption performance of the studied ISS in the removal process of $\mathrm{Sr}^{2+}$ from aqueous solution is presented in Fig. 9 and Fig. 10 for three different temperatures $(298 \mathrm{~K}, 303 \mathrm{~K}$ and $318 \mathrm{~K})$. It can be observed that the adsorption capacities of the both studied materials and for all the studied temperature increase with the contact time increasing until the equilibrium between the adsorbent and adsorbate is reached. We can conclude that the equilibrium is reached in 2 hours of contact.

The kinetic of the adsorption describing the rate of the removal of $\mathrm{Sr}^{2+}$ is one of the important characteristic that defines the efficiency of adsorption. In order to evaluate the kinetic mechanism that controls the adsorption process, the 
pseudo-first-order and pseudo-second-order were tested to interpret the experimental data. Because of the poor regression coefficient $\left(R^{2}\right)$ values of the Lagergren pseudo-first-order model the results are not included in the text.

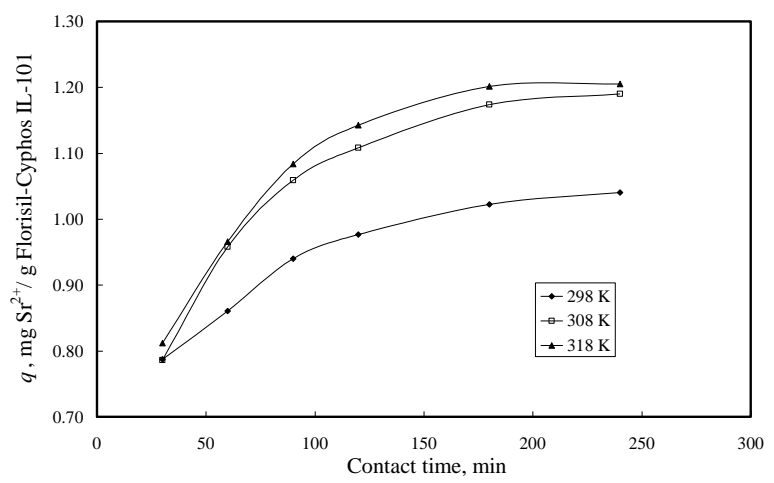

Fig. 9. Effect of contact time on the adsorption capacity of florisil impregnated with Cyphos IL-101

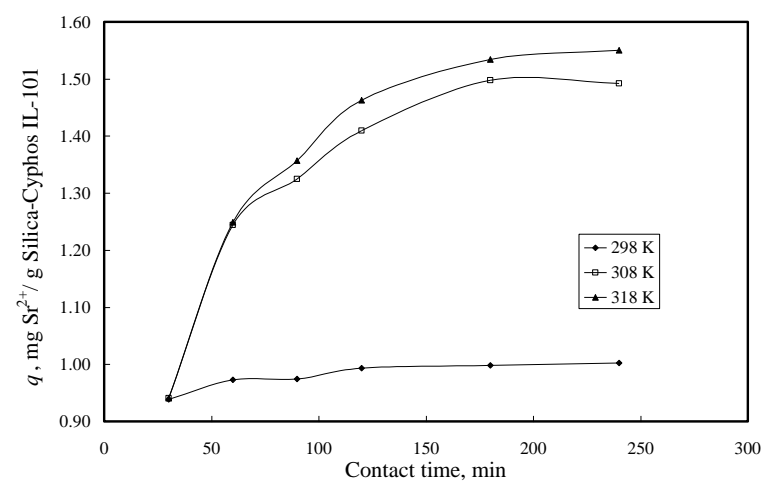

Fig. 10. Effect of contact time on the adsorption capacity of Silica impregnated with Cyphos IL-101

The linear form of the pseudo-second-order rate expression is given by:

$$
\frac{t}{q_{t}}=\frac{1}{k_{2} \cdot q_{e}^{2}}+\frac{t}{q_{e}}
$$

where $k_{2}$ is the pseudo-second-order rate constant $(\mathrm{g} / \mathrm{min} \cdot \mathrm{mg})$. $q_{e}$ the amount of $\mathrm{Sr}^{2+}$ adsorbed $\left(\mathrm{mg} / \mathrm{g}\right.$ ) at equilibrium and $q_{t}$ is the amount of the adsorption $(\mathrm{mg} / \mathrm{g})$ at any time $t$. The pseudo second-order rate constant $k_{2}$ and $q_{e}$ were calculated from the slope and intercept of the plots of $t / q_{t}$ versus $t$ (Fig. 11 and Fig. 12). The experimental and calculated $q_{e}$ values, pseudo-second-order rate constants and $\mathrm{R}^{2}$ values are presented in Table IV.

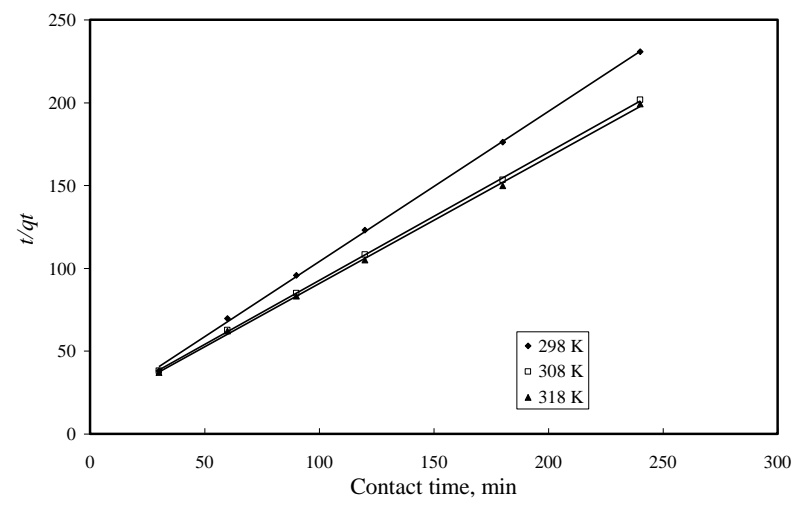

Fig. 11. Pseudo-second-order kinetics plots for $\mathrm{Sr}^{2+}$ adsorption onto florisil impregnated with Cyphos IL-101

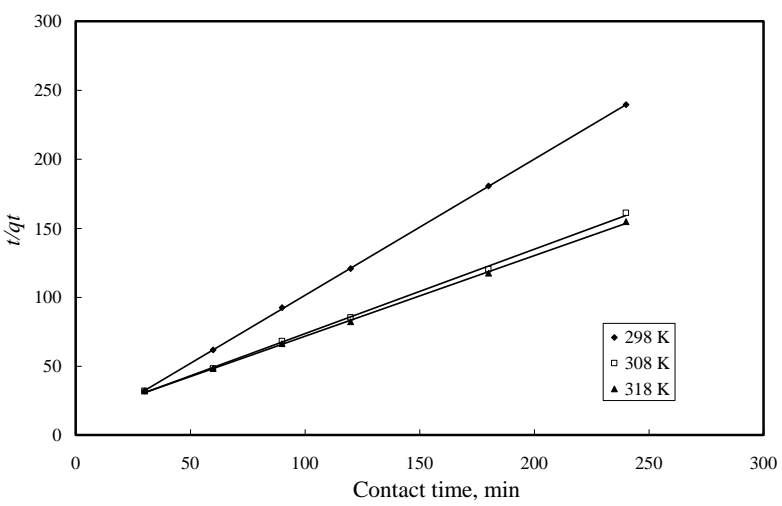

Fig. 12. Pseudo-second-order kinetics plots for $\mathrm{Sr}^{2+}$ adsorption onto silica impregnated with Cyphos IL-101

TABLE IV: PSEUDO-SECOND-ORDER PARAMETERS FOR SR ${ }^{2+}$ ADSORPTION ONTO THE ISS

\begin{tabular}{cccc}
\hline \hline$T(\mathrm{~K})$ & Parameters & $\begin{array}{c}\text { Florisil impregnated } \\
\text { with Cyphos IL-101 }\end{array}$ & $\begin{array}{c}\text { Silica impregnated } \\
\text { with Cyphos IL-101 }\end{array}$ \\
\hline \multirow{2}{*}{298} & $q_{e, \text { exp }}, \mathrm{mg} / \mathrm{g}$ & 1.25 & 1.6 \\
& $q_{e, \text { calc, } \mathrm{mg} / \mathrm{g}} \mathrm{g} /(\mathrm{min} \cdot \mathrm{mg})$ & 1.11 & 1.02 \\
& $\mathrm{R}^{2}$ & 0.0613 & 0.366 \\
& $q_{e, \text { calc, } \mathrm{mg} / \mathrm{g}}$ & 0.9995 & 0.9999 \\
303 & $k_{2}, \mathrm{~g} /(\mathrm{min} \cdot \mathrm{mg})$ & 0.0389 & 1.64 \\
& $\mathrm{R}^{2}$ & 0.9998 & 0.0302 \\
& $q_{e, \text { calc, } \mathrm{mg} / \mathrm{g}}$ & 1.31 & 0.9991 \\
318 & $k_{2}, \mathrm{~g} /(\mathrm{min} \cdot \mathrm{mg})$ & 0.0402 & 0.0257 \\
& $\mathrm{R}^{2}$ & 0.9999 & 0.9994 \\
\hline \hline
\end{tabular}

The calculated $q_{e}$ values are in agreement with the experimental $q_{e}$ values and the plots show good linearity, with $R^{2}$ higher than 0.99 for all both studied adsorbent at all three studied temperatures. Hence, this study suggested that the pseudo-second-order kinetic model better represent the adsorption kinetics, and the adsorption process has the profile of chemisorptions.

\section{CONCLUSION}

In this work the adsorption properties of two new materials, Silica and Florisil impregnated with Cyphos Il-101, was studied in the removal process of $\mathrm{Sr}^{2+}$ from aqueous solutions. The experiments showed that adsorption is depended by the $\mathrm{pH}$, the maximum adsorption capacity being achieved at an initial $\mathrm{pH}$ of solution 6 . The equilibrium data were fitted with the Langmuir and Freundlich isotherm, the best correlation being obtained by the Langmuir one. The maximum sorption capacity obtained by the Florisil impregnated with Cyphos

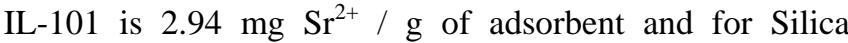
impregnated with Cyphos IL-101 is $3.97 \mathrm{mg} \mathrm{Sr}^{2+} / \mathrm{g}$ of adsorbent, which are higher than other adsorbent material studied in the specialty literature. The kinetic studies revealed that the adsorption process of $\mathrm{Sr}^{2+}$ onto both studied impregnated materials followed the pseudo-second order kinetic model, suggesting the chemisorptions profile of the adsorption process. The entire results showed that the 
obtained new impregnated materials represent efficient adsorbents in the removal process of $\mathrm{Sr}^{2+}$ ions from aqueous solutions.

\section{ACKNOWLEDGMENT}

"This work was supported by a grant of the Romanian National Authority for Scientific Research, CNCS UEFISCDI, project number PN-II-RU-TE-2012-3-0198".

\section{REFERENCES}

[1] M. Wang, L. Xu, J. Peng, M. Zhai, J. Li, and G. Wei, "Adsorption and desorption of $\mathrm{Sr}(\mathrm{II})$ ions in the gels based on polysaccharide derivates,' J. Hazard. Mater., vol. 171, pp. 820-826, November 2009.

[2] S. Chegrouche, A. Mellah, and M. Barkat, "Removal of strontium from aqueous solutions by adsorption onto activated carbon: kinetic and thermodynamic studies," Desalination, vol. 235, pp. 306-318, January 2009.

[3] E. Bascetin and G. Atun, "Adsorption behavior of strontium on binary mineral mixtures of Montmorillonite and Kaolinite," Appl. Radiat. Isotopes, vol. 64, pp. 957-964, August 2006.

[4] S. Yusan and S. Erenturk, "Adsorption characterization of strontium on PAN/Zeolite composite adsorbent," World Journal of Nuclear Science and Technology, vol. 1, pp. 6-12, April 2011.

[5] A. Ghaemi, M. T. Mostaedi, and M. G. Maragheh, "Characterizations of strontium (II) and barium (II) adsorption from aqueous solution using dolomite powder," J. Hazard. Mater., vol. 190, pp. 916-921, June 2011.

[6] C. Xu, X. Shen, Q. Chen, and H. Gao, "Investigation on the extraction of strontium ions from aqueous phase using crown ether-ionic liquid systems," Science in China Series B: Chemistry, vol. 52, no. 11, pp. 1858-1864, November 2009.

[7] C. A. Kozlowski, J. Kozlowska, W. Pellowski, and W. Walkowiak, "Separation of cobalt-60, strontium-90, and caesium-137 radioisotopes by competitive transport across polymer inclusion membranes with organophosphorous acids," Desalination, vol. 198, pp. 140-148, October 2006.

[8] A. Zhang, W. Wang, Z. Chai, and E. Kuraoka, "Modification of a novel macroporous Silica-based crown ether impregnated polymeric composite with 1-dodecanol and its adsorption for some fission and non-fission product contained in high level liquid waste," European Polymer Journal, vol. 44, pp. 3899-3907, November 2008.

[9] A. Zhang, C. Xiao, E. Kuraoka, and M. Kumagai, "Mollecular modifiction of a novel macroporous silica-based impregnated polymeric composite by tri-n-butyl phosphate and its application in the adsorption for some metals contained in a typical simulated HLLW," $J$. Hazard. Mater., vol. 147, pp. 601-609, August 2007.

[10] X. Sun, Y. Li, J. Chen, and J. Ma, "Solvent impregnated resin prepared using task-specific ionic liquids for rare earth separation," Journal of Rare Earths, vol. 27, no. 6, pp. 932-936, September 2009.

[11] Y. Liu, L. Zhu, X. Sun, J. Chen, and F. Luo, "Silica materials doped with bifunctional ionic liquid extractants for Yttrium extraction," Industrial and Engineering Chemistry Reearch, vol. 48, pp. 7308-7313, July 2009.

[12] V. Gallardo, R. Navarro, I. Saucedo, M. Avila, and E. Guibal, "Zinc(II) extraction from hydrochloric acid solutions using Amberlite XAD7 impregnated with Chyphos IL101 (tetradecyl(trihexyl) phosphonium chloride)," Separation Science and Technology, vol. 43, pp. 2434-2459, August 2008

[13] H. T. Huynh and M. Tanak, "Removal of Bi, Cd, Co, Cu, Fe, Ni, Pb, Zn from an aqoueous nitrate medium with bis(2-ethylhexyl)phosphoric acid impregnated kapok fiber," Industrial and Engineering Chemistry Research, vol. 42, pp. 4050-4054, July 2003.

[14] K. Campos, R. Domingo, T. Vincent, M. Ruiz, A. M. Sastre, and E. Guibal, "Bismuth recovery from acidic solutions using Cyphos IL-101 immobilized in a composite biopolymer matrix," Water Research, vol. 42, pp. 4019-4031, August 2008.

[15] S. D. Cekic, H. Filik, and R. Apak, "Use of an o-aminobenzoic acid-functionalized XAD-4 copolymer resin for the separation and preconcentration of heavy metal (II) ions," Analytica Chimica Acta, vol. 505, pp. 15-24, March 2004.

[16] L. Zhu, L. Guo, Z. Zhang, J. Chen, and S. Zhang, "The preparation of supported ionic liquids (SILs) and their application in rare metals separation," Science China Chemistry, vol. 55, no. 8, pp. 1479-1487, July 2012.

[17] L. Zhu, C. Zhang, Y. Liu, D. Wang, and J. Chen, "Direct synthesis of ordered N-methylimidazolium functionalized mesoporous Silica as highly efficient anion exchanger of Cr(VI)," Journal of Materials Chemistry, vol. 20, pp. 1553-1559, February 2010.

[18] A. Nilchi, R. Saberi, M. Moradi, H. Azizpour, and R. Zarghami, "Adsorption of cesium on copper hexacyanoferrate-PAN composite ion exchanger from aqueous solution," Chemical Engineering Journal, vol. 172, pp. 572-580, August 2011.

[19] Y. Liu, L. Zhu, X. Sun, J. Chen, and F. Luo, "Silica materials doped with bifunctional ionic liquid extractants for Yttrium extraction," Industrial and Engineering Chemistry Reearch, vol. 48, pp. 7308-7313, July 2009.

[20] M. E. Mahmoud, "Surface loaded 1-methyl-3-ethylimidazolium bis(trifluoromethylsulfonyl)imide $\left[\mathrm{EMIM}^{+} \mathrm{Tf}_{2} \mathrm{~N}^{-}\right]$hydrophobic ionic liquid on nano-Silica sorbents for removal of lead from water samples,' Desalination, vol. 266, pp. 119-127, January 2011.

[21] S. P. Mishra and V. K. Singh, "Radiotracer technique in adsorption study XIII> Adsorption of barium and strontium ions on chromium (IV) oxide powder," Applied Radiat Isotopes, vol. 46, pp. 847-853, September 1995

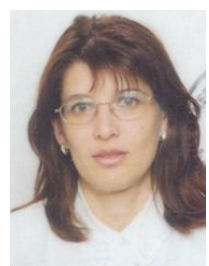

Adina Negrea was born September 19, 1967 in Hunedoara, Romania. She is currently a lecturer at Faculty of Industrial Chemistry and Environmental Engineering, University Politehnica Timisoara, Romania. She has obtained her $\mathrm{PhD}$ diploma in Engineering Science in 2002. Teaching and research interest within the environmental engineering and waste waters treatment

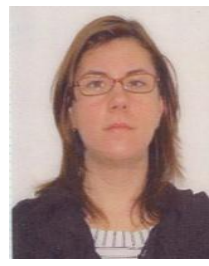

Lavinia Lupa was born June 29, 1980 in Deva Romania. She is currently a teaching assistant at Faculty of Industrial Chemistry and Environmental Engineering, University Politehnica Timisoara, Romania. She has obtained her $\mathrm{PhD}$ diploma in Engineering Science in 2008. Teaching and research interest within the environmental engineering and waste waters treatment.

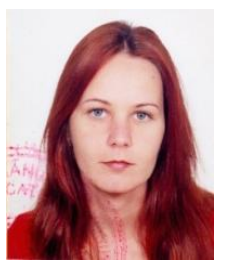

Mihaela Ciopec was born October 8, 1977 in Timisoara, Romania. She is a currently scientific researcher at Faculty of Industrial Chemistry and Environmental Engineering, University Politehnica Timisoara, Romania. She has obtained her $\mathrm{PhD}$ diploma in Engineering Science in 2008. Teaching and research interest within the environmental engineering and waste waters treatment.

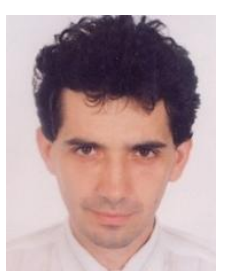

Petru Negrea was born July 7, 1967 in Resita, Romania. He is currently a professor at Faculty of Industrial Chemistry and Environmental Engineering, University Politehnica Timisoara, Romania. He has obtained his PhD diploma in Engineering Science in 1996. Teaching and research interest within the chemical engineering and environmental protection. 